\title{
Effect of oral mexiletine on the cough response to capsaicin and tartaric acid
}

\author{
Masaki Fujimura, Yumie Kamio, Shigeharu Myou, Takuma Hashimoto
}

\begin{abstract}
Background-The effect of the orally active local anaesthetic mexiletine on the cough response to two different tussive agents, a C-fibre ending stimulator capsaicin and a chemostimulant tartaric acid, was examined in normal subjects.

Methods-The cough threshold, defined as the lowest concentration of capsaicin $\left(\mathrm{C}_{5}-\mathrm{CP}\right)$ or tartaric acid $\left(\mathrm{C}_{5}-\mathrm{TA}\right)$ causing five or more coughs, and histamine induced bronchoconstriction were measured three hours after a single oral dose of $300 \mathrm{mg}$ mexiletine or placebo in 14 normal subjects.

Results-Mexiletene in a mean (SE) serum concentration of $0.99(0.04) \mu \mathrm{g} / \mathrm{ml}$ significantly increased $\mathrm{C}_{5}$-TA from a geometric mean (SE) of 32.0 (1.27) $\mathrm{mg} / \mathrm{ml}$ with placebo to $49.9(1.34) \mathrm{mg} / \mathrm{ml}$, but $\mathrm{C}_{5}$-CP did not differ significantly between treatment with mexiletine (12.2 (1.33) $\mu M$ ) and placebo (14.9 (1.23) $\mu M)$.

Conclusions-These results suggest that the cough response to capsaicin and tartaric acid may be mediated in part via different neural pathways.

(Thorax 2000;55:126-128)
\end{abstract}

Keywords: cough response; mexiletine; capsaicin; tartaric acid

Third Department of Internal Medicine, Kanazawa University School of Medicine, 13-1 Takara-machi, Kanazawa 920, Japan

M Fujimura

S Myou

Department of Laboratory Medicine, Kanazawa University School of Medicine

T Hashimoto

Pulmonary Function Laboratory, The

Central Laboratory, Kanazawa University Hospital, Kanazawa, Japan

Y Kamio

Correspondence to: Dr M Fujimura

Received 9 April 1999 Returned to authors 23 June 1999

Revised version received 14 October 1999

Accepted for publication

4 November 1999
Cough elicited by inhaled tussive agents is mediated via neural pathways. Irritant receptors, and possibly C-fibre endings, are generally recognised as cough receptors in the airways. ${ }^{1}$ Capsaicin is the active ingredient of red pepper and has been presumed to produce cough mainly by stimulating C-fibre endings, ${ }^{2}$ though its action may be indirect. ${ }^{1}$ In contrast, although tartaric acid and citric acid are chemostimulants that have been postulated to induce cough by stimulating irritant receptors, it has been shown that the capsaicin receptor antagonist capsazepine inhibits cough induced by citric acid as well as capsaicin. ${ }^{3}$ Thus, it remains unclear whether capsaicin and chemostimulants elicit cough through different neural pathways.

Mexiletine is an orally active local anaesthetic agent. It has been shown that a single oral dose of mexiletine reduces histamine induced reflex bronchoconstriction by the same degree as intravenous lidocaine in subjects with mild asthma. ${ }^{4}$ Thus, oral mexiletine is useful in investigating the effects of local anaesthetics on various airway functions because aerosol administration of these drugs can in itself cause an initial bronchoconstriction ${ }^{5}$ and may influence the cough response to tussive agents.

We therefore investigated whether oral administration of mexiletine could reduce the cough response to inhaled capsaicin and tartaric acid in normal subjects. We also examined the inhibitory effect of mexiletine on histamine induced bronchoconstriction to confirm that the tested dose is adequate.

\section{Methods}

SUBJECTS

Fourteen normal young women with a mean (SE) age of 20.4 (0.2) years (range 20-22) were selected from 20 non-smoking university students who underwent histamine, capsaicin, and tartaric acid challenge tests during a three week run in period before entering the study. The 14 subjects selected had a histamine $\mathrm{PC}_{20}$ value (concentration of histamine producing a $20 \%$ fall in $\mathrm{FEV}_{1}$ ) of $<40 \mathrm{mg} / \mathrm{ml}$. Informed consent was obtained from all subjects and the study was approved by the ethics committee of the Kanazawa University Hospital.

MEASUREMENT OF COUGH SENSITIVITY

Cough sensitivity to capsaicin and tartaric acid were measured by the method described previously. ${ }^{6}$ Tartaric acid (Wako Pure Chemical Industries Ltd, Tokyo, Japan) was dissolved in physiological (normal) saline to give concentrations of $1.56,3.12,6.25,12.5,25,50,100$, 200, 400, and $800 \mathrm{mg} / \mathrm{ml}$. Capsaicin (30.5 mg) was dissolved in Tween $80(1 \mathrm{ml})$ and ethanol $(1 \mathrm{ml})$ and then in normal saline $(8 \mathrm{ml})$ to make a stock solution of $3.05 \mathrm{mg} / \mathrm{ml}(1 \times$ $10^{-2} \mathrm{M}$ ) which was stored at $-20^{\circ} \mathrm{C}$. This solution was diluted with physiological saline to give solutions of $0.49,0.98,1.95,3.9,7.8$, $15.6,31.2,62.5,125,250,500$, and $1000 \mu \mathrm{M}$. Subjects inhaled progressively increasing concentrations of the tartaric acid or the capsaicin solution for 15 seconds by mouth tidal breathing every 60 seconds from a Bennett twin nebuliser (3012-60 ml, Puritan-Bennett Company, Carlsbad, California, USA), inhaling increasing concentrations until they coughed at least five times. The nebuliser output was $0.21 \mathrm{ml} / \mathrm{min}$. It has been reported that the aerodynamic mass median diameter (MMD) of the particles is $3.60 \mu \mathrm{m}$ with a geometric standard deviation of $3.47 .^{7}$ The number of coughs induced by capsaicin or tartaric acid was counted by two medical technicians. The cough threshold was defined as the lowest concentration of capsaicin $\left(\mathrm{C}_{5}-\mathrm{CP}\right)$ or tartaric acid $\left(\mathrm{C}_{5}\right.$-TA) that elicited five or more coughs. ${ }^{6}$ 

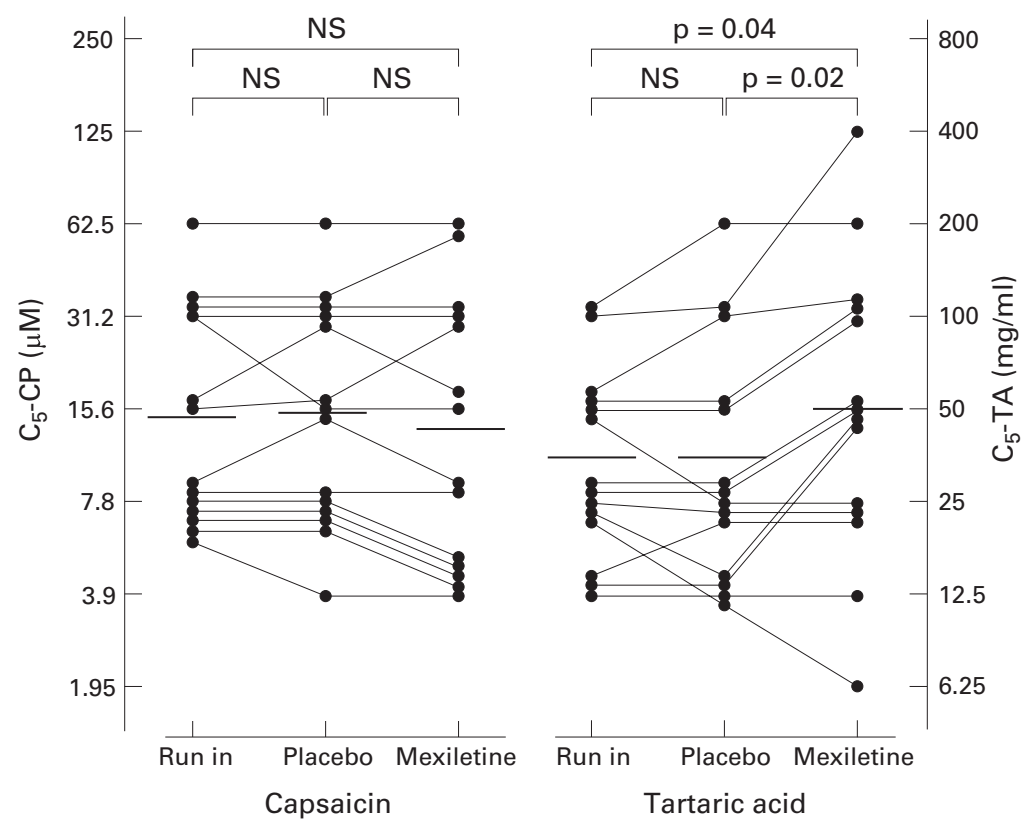

Figure 1 Cough threshold to inhaled capsaicin $\left(C_{5}-C P\right)$ and tartaric acid $\left(C_{5}-T A\right)$ in each subject in the run in period (baseline) and three hours after an oral dose of mexiletine and placebo. Each horizontal bar represents a geometric mean value.

\section{MEASUREMENT OF HISTAMINE INDUCED}

BRONCHOCONSTRICTION

Histamine dihydrochloride (Sigma Chemical Company, St Louis, Missouri, USA) was dissolved in physiological saline to make solutions of $0.04,0.08,0.16,0.31,0.63,1.25$, $2.5,5,10,20,40,80$ and $160 \mathrm{mg} / \mathrm{ml}$. Histamine was inhaled for two minutes by tidal mouth breathing from a DeVilbiss No. 646 nebuliser (DeVilbiss Co, Somerset, Pennsylvania, USA) operated by compressed air at $5 \mathrm{l} / \mathrm{min}$, immediately followed by measurement of forced expiratory volume in one second $\left(\mathrm{FEV}_{1}\right)$ (Transfer Test, $\mathrm{P} \mathrm{K}$ Morgan Ltd,

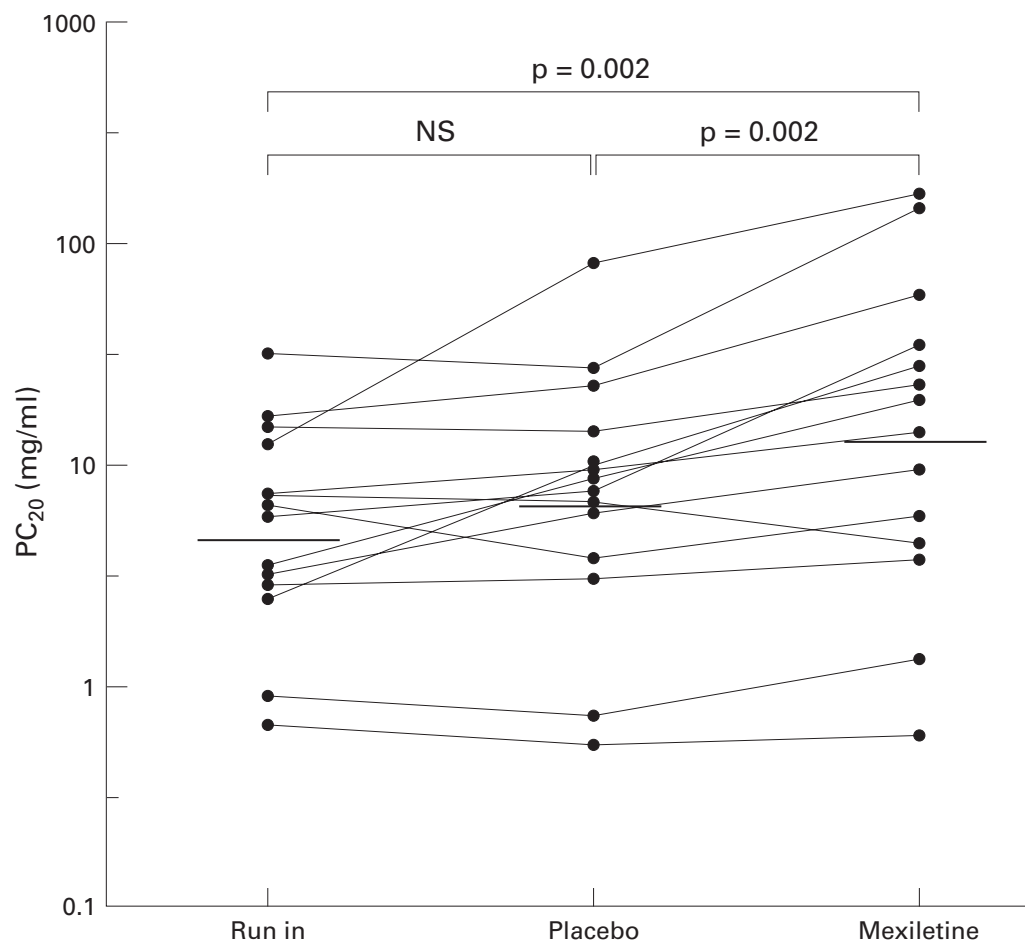

Figure 2 Histamine $P C_{20}$ value in each subject in the run in period (baseline) and three hours after an oral dose of mexiletine and placebo. Each horizontal bar represents a geometric mean value.
Chatham, UK). Increasing concentrations of histamine were successively inhaled until a fall of $20 \%$ or more in the $\mathrm{FEV}_{1}$ occurred. $\mathrm{PC}_{20}$ values were determined by linear interpolation from the log dose response curve.

STUDY PROTOCOL

On six subsequent visits seven days apart, in random order and in a double blind fashion, the subjects took three capsules at 11.00 hours (either $300 \mathrm{mg}$ mexiletine or placebo). The order of measurement of the cough threshold to capsaicin and tartaric acid and bronchial responsiveness to histamine was also randomised. Each subject attended at 13.30 hours on the six separate days. After resting for 30 minutes challenge with capsaicin, tartaric acid, or histamine was started.

Immediately after the histamine challenge serum was collected from each subject in order to examine the serum concentration of mexiletine which was measured by ELISA.

\section{DATA ANALYSIS}

Values for $\mathrm{C}_{5}-\mathrm{CP}, \mathrm{C}_{5}-\mathrm{TA}$ and $\mathrm{PC}_{20}$ were presented as geometric means with geometric standard errors (GSE). Changes in $\mathrm{C}_{5}-\mathrm{CP}$, $\mathrm{C}_{5}-\mathrm{TA}$, and $\mathrm{PC}_{20}$ by treatment with mexiletine in each subject were shown in doubling concentrations, which were calculated as $\log _{2}$ (the value with mexiletine/the value with placebo) and presented as arithmetic means (SE). Geometric mean values for $\mathrm{C}_{5}-\mathrm{CP}$, $\mathrm{C}_{5}$-TA, and $\mathrm{PC}_{20}$ were compared during the run in period and during treatment with mexiletine and with placebo by the Student's paired $t$ test. Simple regression analysis was employed in assessing the relationship between the parameters. Significance was based on a $95 \%$ confidence level $(\mathrm{p}<0.05)$.

\section{Results}

The values for $\mathrm{C}_{5}-\mathrm{CP}, \mathrm{C}_{5}-\mathrm{TA}$, and $\mathrm{PC}_{20}$ were not significantly different between the run in period and on the first and second visits. The geometric mean (SE) values for $\mathrm{C}_{5}-\mathrm{CP}$ were 13.5 (1.23) $\mu \mathrm{M}$ during the run in period and 14.9 (1.23) $\mu \mathrm{M}$ and 12.2 (1.33) $\mu \mathrm{M}$ with placebo and mexiletine, respectively (fig 1 ). The $\mathrm{C}_{5}$-TA value with mexiletine was 49.9 (1.34) $\mathrm{mg} / \mathrm{ml}$, which was significantly greater than that with placebo $(32.0(1.27) \mathrm{mg} / \mathrm{ml})$ (doubling concentration $0.64(0.25), \mathrm{p}=0.02)$ and that during the run in period (32.0 (1.20) $\mathrm{mg} / \mathrm{ml}$ (doubling concentration 0.64 (0.29), $\mathrm{p}=0.04$; fig 1 ). There was a significant correlation between $\mathrm{C}_{5}-\mathrm{CP}$ and $\mathrm{C}_{5}-\mathrm{TA}$ values during the run in period $(r=0.737, \mathrm{p}=0.003)$ and during treatment with placebo $(r=0.707$, $\mathrm{p}=0.005)$. On the other hand, the correlation coefficient between $\mathrm{C}_{5}$-CP during the run in period and during placebo treatment was $0.880(\mathrm{p}<0.0001)$, and between $\mathrm{C}_{5}$-TA during the run in period and during placebo treatment was $0.849(\mathrm{p}=0.0001)$.

The geometric mean (SE) $\mathrm{PC}_{20}$ values were $5.08(1.33) \mathrm{mg} / \mathrm{ml}$ during the run in period and $7.08(1.42) \mathrm{mg} / \mathrm{ml}$ and $13.4(1.55) \mathrm{mg} / \mathrm{ml}$ during treatment with placebo and mexiletine, respectively (fig 2 ). The value with mexiletine 
was significantly greater than that with placebo (doubling concentration $0.90 \quad(0.23), \mathrm{p}=$ 0.002 ) and that in the run in period (doubling concentration $1.38(0.35), p=0.002)$. The serum concentration of mexiletine immediately after completing the histamine challenge was $0.99(0.04) \mu \mathrm{g} / \mathrm{ml}$ (therapeutic range 0.7 $2.0 \mu \mathrm{g} / \mathrm{ml})$.

After administration of mexiletine five subjects complained of mild to severe dizziness which had disappeared completely by the next morning. Each patient also felt nauseous and sleepy.

\section{Discussion}

This study has shown that oral mexiletine reduces cough sensitivity to inhaled tartaric acid, but not to capsaicin, and decreases histamine induced bronchoconstriction in nonasthmatic subjects. The latter result is in agreement with Groeben and coworkers. ${ }^{4}$ The serum concentrations of mexiletine were in the therapeutic range for cardiac protection against dysrhythmias. It is suggested that tartaric acid induced cough may be mediated in part via the same neural pathway as histamine induced reflex bronchoconstriction in normal subjects, whereas the neural pathway may not be involved in capsaicin induced cough.

Local anaesthetics may influence airway responses such as bronchial responsiveness and cough sensitivity by several mechanisms, including direct airway smooth muscle relaxation, inhibition of mediator release from inflammatory and resident cells in the airways, central nervous system depression, and neural blockade of vagal reflex pathways. Although the direct effects of local anaesthetics on airway smooth muscle tone and mediator release from inflammatory cells have been shown in vitro, the drug concentration necessary to achieve these effects was more than 100 times greater than the concentration used clinically. ${ }^{89}$ It is possible that severe depression of the central nervous system suppresses the airway responses, but it has been reported that lidocaine prevents reflex induced cough in anaesthetised subjects. ${ }^{10}$ Accordingly, it is thought that the major mechanism by which mexiletine reduces tartaric acid induced cough and histamine responsiveness is by neural blockade of vagal reflex pathways.

Histamine causes both direct airway smooth muscle contraction and vagally mediated reflex constriction. ${ }^{11}$ Brown et $a l^{12}$ have shown in a dog model that local anaesthetics are effective in blocking neurally mediated reflex induced airway constriction, whereas they are ineffective in preventing direct airway smooth muscle contraction induced by methacholine. In asthmatic subjects it has been clearly shown that oral mexiletine blocks reflex mediated histamine induced bronchoconstriction, as does intravenous lidocaine. ${ }^{4}$ We therefore examined the effect of oral mexiletine on histamine induced bronchoconstriction to confirm that the drug in the tested dose blocks reflex mediated bronchoconstriction in non-asthmatic subjects.
Local anaesthetics prevent sensory nerve traffic in both myelinated and non-myelinated nerves and are the most consistently effective antitussive agents, ${ }^{13}$ but the effects of anaesthetics on the cough response to tussive agents have been controversial. Cross and colleagues ${ }^{14}$ reported that bupivacaine administered by inhalation, but not by intravenous infusion, reduced the cough induced by citric acid aerosol in man, suggesting a different effect between local and systemic administration of anaesthetics. Choudry et $a l^{15}$ have shown that inhalation of lidocaine, but not dyclonine, reduces the cough response to inhaled capsaicin at doses that do not affect reflex bronchoconstriction in humans, while both lidocaine and dyclonine cause significant reports of oral anaesthesia which suggests that the inhibitory effect of lidocaine may be mediated by the sensory pathways that are unaffected by dyclonine. In the present study oral administration of mexiletine inhibited both the cough response to inhaled tartaric acid and histamine induced bronchoconstriction, but did not alter capsaicin induced cough. In addition, the relationship between the cough threshold to capsaicin and tartaric acid was relatively weaker than that to each cough stimulant between the run in period and placebo treatment. These findings suggest that inhaled capsaicin and tartaric acid cause cough via somewhat different neural pathways and that the histamine induced reflex bronchoconstriction may be mediated in part by the same neural pathway as tartaric acid induced cough.

1 Widdicombe JG. Neurophysiology of the cough reflex. Eur Respir F 1995;8:1193-202.

2 Fuller RW, Jackson DM. Physiology and treatment of cough. Thorax 1990;45:425-30.

3 Lalloo UG, Fox AJ, Belvisi MG, et al. Capsazepine inhibits cough induced by capsaicin and citric acid but not by hypertonic saline in guinea pigs. $\mathcal{F}$ Appl Physiol 1995;79: $1082-7$.

4 Groeben H, Foster WM, Brown RH. Intravenous lidocaine and oral mexiletine block reflex bronchoconstriction in asthmatic subjects. Am ₹ Respir Crit Care Med 1996;154: $885-8$

5 Miller WC, Awe R. Effect of nebulized lidocaine on reactive airways. Am Rev Respir Dis 1975;111:739-41.

6 Fujimura M, Sakamoto S, Kamio Y, et al. Effects of methacholine-induced bronchoconstriction and procaterol-induced bronchodilation on cough receptor sensitivity to inhaled capsaicin and tartaric acid. Thorax 1992;47:441-5.

7 Ryan G. Standardization of inhalation provocation tests: influence of nebulizer output, particle size, and method of inhalation. 7 Allergy Clin Immunol 1981;67:156-61.

8 Kai T, Nishimura J, Kobayashi S, et al. Effects of lidocaine on intracellular $\mathrm{Ca}^{2+}$ and tension in airway smooth muscle. Anesthesiology 1993;78:954-65.

9 Downes H, Loehning RW. Local anesthetic contracture and relaxation of airway smooth muscle. Anesthesiology 1977; 47:430-6.

10 Nishino T, Hiraga K, Sugimori K. Effects of i.v. lignocaine on airway reflexes elicited by irritation of the tracheal mucosa in humans anaesthetized with enflurane. $B r F^{\prime}$ Anaesth 1990;64:682-7.

11 Ruffin RE, Dolovich MB, Wolff RK, et al. The effects of preferential deposition of histamine in the human airway. preferential deposition of histamine

12 Brown R H, Robbins W, Staats P, et al. Prevention of bronchoconstriction by an orally active local anesthetic. Am F Respir Crit Care Med 1995;151:1239-43.

13 Karlsson JA. Airway anaesthesia and the cough reflex. Bull Eur Physiopathol Respir 1983;23(Suppl 10):29-36S.

14 Cross BA, Guz A, Jain SK, et al. The effect of anaesthesia of the airway in dog and man: a study of respiratory reflexes, sensations and lung mechanics. Clin Sci Mol Med 1976;50: 439-54.

15 Choudry NB, Fuller RW, Anderson N, et al. Separation of cough and reflex bronchoconstriction by inhaled local anaesthetics. Eur Respir f 1990;3:579-83. 